\title{
A Influência do Tempo de Atuação da Polaridade Positiva na Soldagem TIG CA do Alumínio
}

\author{
(The Influence of Positive Polarity Time on AC-GTAW of Aluminum)
}

\author{
Luciano Machado Cirino ${ }^{1}$, Jair Carlos Dutra ${ }^{1}$ \\ ${ }^{1}$ Universidade Federal de Santa Catarina, Faculdade de Engenharia Mecânica, Florianópolis, SC, Brasil, \\ lucianocirino@labsolda.ufsc.br, jdutra@labsolda.ufsc.br
}

\begin{abstract}
Resumo
Neste trabalho, experimentos foram conduzidos para determinar o comportamento de fusão do alumínio 1200 diante do aumento do tempo de atuação da polaridade positiva na soldagem TIG CA deste metal. Para atingir este objetivo, foi desenvolvido um conjunto de experimentos, de tal forma que a intensidade da corrente elétrica na polaridade positiva e negativa foi a mesma; apenas os tempos de duração de cada polaridade eram modificados. Durante os experimentos foram realizadas aquisições dos sinais de corrente e tensão. Por intermédio destes foi possível determinar a tensão e a potência de arco para cada condição testada. No aspecto comportamento de fusão, um aumento na penetração e nas áreas de fusão foi verificado à medida que maiores tempos de polaridade positiva eram utilizados. Este comportamento difere daquele indicado comumente pela literatura sobre processos de soldagem com eletrodos nãoconsumiveis, que infere uma diminuição na penetração com o aumento do tempo de atuação da polaridade positiva. Entretanto, esta tendência crescente constatada durante os experimentos ocorre a partir de um determinado ponto, onde os tempos de atuação da polaridade positiva são maiores do que 4,0 ms em um periodo total de 20,0 ms. O uso de um tempo mínimo de polaridade positiva (1,3 ms) mostrou-se eficiente em realizar a limpeza catódica, produziu soldas com características de fusão satisfatórias e com desgaste mínimo do eletrodo de tungstênio. A boa capacidade de fusão obtida em soldas realizadas com altos tempos de atuação da polaridade positiva foi atribuída a fenômenos decorrentes da emissão de elétrons por efeito de campo que ocorre durante as fases de eletrodo positivo.
\end{abstract}

Palavras-chave: $T I G$ CA, limpeza catódica, emissão termiônica, efeito de campo

\begin{abstract}
In this work, experiments were carried out to determine the fusion behavior of 1200 aluminum with an increase in the positive polarity time in the VP-GTAW of this metal. To achieve this objective, a set of experiments was developed, in such way that the electrical current intensity was the same in both the positive and negative polarity; only the lengths in each polarity were modified. During the experiments the acquisition of the current and voltage signals was performed. Through these it was possible to determine the arc voltage and power for each condition tested. In relation to the fusion behavior there was an increase in the weld depth and fusion zones when longer positive polarity times were used. This behavior differs from the literature relating to welding processes with non-consumable electrodes, which suggest a decrease in the weld depth with an increase in the positive polarity acting time. However, the increase noticed during the experiments occurs from a certain point, when the positive polarity time is longer than 4.0 ms over a total period of $20.0 \mathrm{~ms}$. The use of a minimal electrode positive time $(1.3 \mathrm{~ms})$ was found to be sufficient to perform the oxide removal, yielding weld beads with satisfactory fusion characteristics and with minimal wear of the tungsten electrode. The good melt capacity obtained in the welds carried out with high positive polarity times, was attributed to phenomena related to the field emission of electrons which takes place in the current positive half cycles.
\end{abstract}

Key-Words: $A C$-GTAW, cathodic cleaning, thermionic emission, field emission

\section{Introdução}

O processo TIG (Tungsten Inert Gas) se caracteriza por um arco voltaico estabelecido entre um eletrodo de tungstênio, dito não-consumível, e a peça a ser soldada, o que em alguns casos permite a soldagem de chapas metálicas finas (abaixo de $3 \mathrm{~mm}$ ) sem utilização de metal de adição. Metais ferrosos, tais

(Recebido em 25/09/2008; Texto Final em 24/05/2009). como o aço inoxidável, são soldados na condição CC- (corrente contínua e eletrodo conectado ao terminal negativo da fonte de soldagem). Nesta condição, a corrente é conduzida através do plasma, parcialmente por íons e principalmente por elétrons que são emitidos a partir do eletrodo de tungstênio (cátodo) [1]. O tungstênio é um metal que pode atingir temperaturas extremamente altas em sua superfície, o que permite que estes elétrons sejam emitidos por efeito termiônico quando a energia acumulada supera um dado valor necessário (relacionada com a função-trabalho do material) [2]. Quando emitindo elétrons 
termionicamente, a mancha catódica (onde os mecanismos de emissão ocorrem) localizada na ponta do eletrodo de tungstênio apresenta uma densidade de corrente que, segundo Lancaster [3], deve estar entre $10^{6}$ e $10^{8} \mathrm{~A} / \mathrm{m}^{2}$. A Equação (1), conhecida como equação de Richardson-Dushman, mostra que maiores densidades de corrente são atingidas quanto maior for a temperatura do cátodo e menor a sua função-trabalho. Portanto, quanto mais alta a temperatura que o cátodo pode atingir, mais fácil atingirá a faixa de densidade de corrente característica da emissão termiônica.

$$
J=A T^{2} e^{-\frac{\phi}{k T}}
$$

Onde:

$J=$ Densidade de corrente resultante da emissão de elétrons por efeito termiônico.

$A=$ Constante característica do eletrodo.

$T=$ Temperatura na superfície do cátodo (geralmente se considera a temperatura de ebulição do material).

$\phi=$ Função-Trabalho do material.

$k=$ Constante de Boltzmann.

A condição CC- produz um arco bastante estável e suave, o que em muito se deve ao fato de a mancha catódica estar em uma posição fixa na ponta do eletrodo de tungstênio e, apesar da alta temperatura atingida, o desgaste provocado é muito pequeno. $\mathrm{O}$ mesmo não ocorre na condição $\mathrm{CC}+$ (corrente contínua e eletrodo conectado ao terminal positivo da fonte de soldagem). Nesta condição, o principal provedor de elétrons é o próprio metal de base. Nesta situação, a emissão de elétrons não mais ocorre por intermédio do mecanismo termiônico, pois os metais comumente usados em estruturas não atingem as temperaturas necessárias para tal. A emissão de elétrons ocorre pelo estabelecimento de um forte campo elétrico em uma região microscópica sobre a superfície da peça (região de queda catódica), que geralmente excede $10^{9} \mathrm{~V} / \mathrm{m}$ [2]. Este mecanismo de emissão a partir de um catodo não-termiônico é conhecido como efeito de campo. A mancha catódica, antes localizada na ponta do eletrodo, adquire um padrão aleatório de movimentação, produzindo um arco bastante instável. O desgaste provocado no eletrodo de tungstênio é agora muito mais pronunciado.

Entretanto, a condição $\mathrm{CC}+$ possui uma característica extremamente útil na soldagem de metais como o magnésio e o alumínio. O último, quando em contato com o ar atmosférico, produz uma camada microscópica de óxido $\left(\mathrm{Al}_{2} \mathrm{O}_{3}\right)$ em sua superfície. Esta camada possui um ponto de fusão de $2060^{\circ} \mathrm{C}$, $1410{ }^{\circ} \mathrm{C}$ acima do ponto de fusão do substrato [4]. Na condição $\mathrm{CC}-$, o arco voltaico pode atingir temperaturas extremamente altas (acima de $6000 \mathrm{~K}$ ) o que leva a supor que a camada de $\mathrm{Al}_{2} \mathrm{O}_{3}$ seria facilmente fundida. Tal fato não ocorre, pois o alumínio tem uma condutividade térmica muito alta, quando comparada com a do aço inoxidável, por exemplo, de modo que todo o calor projetado sobre a superfície da peça difunde-se rapidamente através desta e não permite a fusão da camada de $\mathrm{Al}_{2} \mathrm{O}_{3}$. Ou seja, não é possível focar calor suficiente em um ponto para produzir fusão da camada de óxidos e, conseqüentemente, a fusão do substrato ocorre de maneira deficiente. A Figura 1 mostra a comparação entre a condição $\mathrm{CC}$ - e $\mathrm{CC}+$, onde é caracterizado que a área de contato entre o arco e a superfície da peça de trabalho é muito maior em A1 (mancha anódica) do que em A2 (mancha catódica). Com isso, supõe-se que, para uma dada corrente de soldagem, tenha-se uma densidade de energia muito maior em A2 $(\mathrm{CC}+)$. Esta energia é, provavelmente, insuficiente para que ocorra a emissão de elétrons por intermédio do mecanismo termiônico, mas é suficientemente concentrada para que ocorra a fusão ou rompimento da camada de $\mathrm{Al}_{2} \mathrm{O}_{3}$.

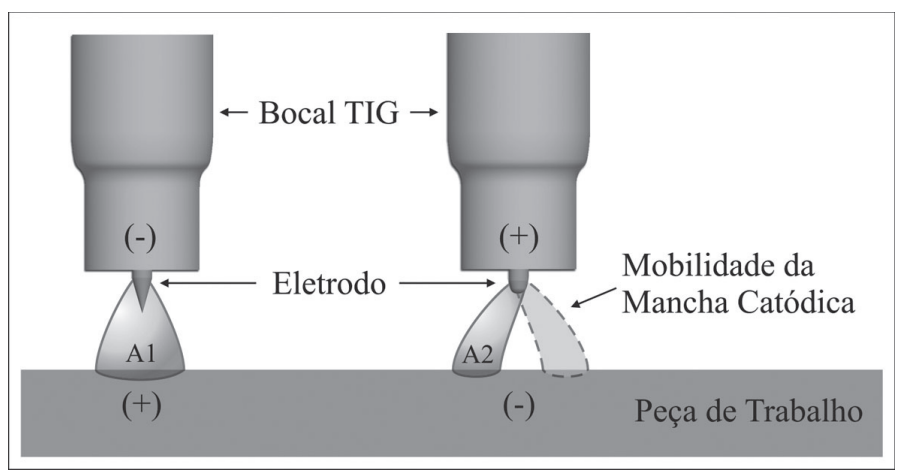

Figura 1. A1) Área de atuação do arco voltaico sobre a superfície da peça a ser soldada na condição CC-; A2) Área de atuação móvel do arco voltaico sobre a superfície da peça na condição $\mathrm{CC}+$.

Este fenômeno é comumente conhecido como limpeza catódica, e tem grande importância técnica na soldagem do alumínio. Contudo, a manutenção de uma operação de soldagem utilizando o eletrodo de tungstênio conectado exclusivamente ao pólo positivo, é na prática, bastante difícil, devido à instabilidade de arco e ao intenso desgaste do eletrodo. Desta forma, é empregada uma situação mista, onde ocorre a alternância entre as condições CC+ e CC-. Esta situação mista é algumas vezes denominada de corrente com polaridade variável, devido às formas retangulares com que as modernas fontes de soldagem produzem a corrente alternada (Figura 2). Com isso, os mecanismos de emissão se alternam entre o efeito termiônico e o efeito de campo, tornando possível um balanceamento de todos os efeitos envolvidos.

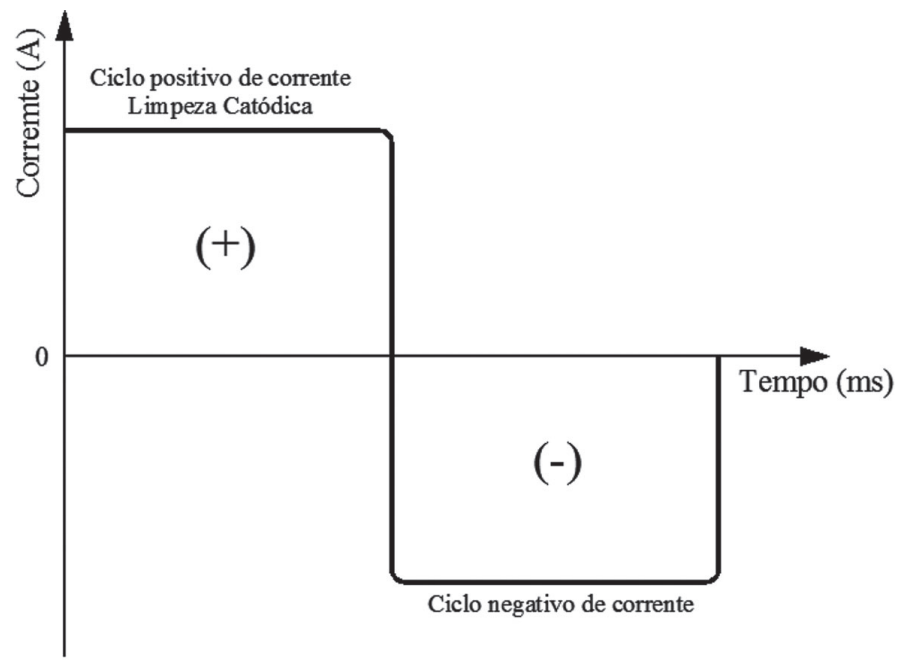

Figura 2. Formato de onda retangular balanceada (regulada em $50 \%$ eletrodo positivo e $50 \%$ eletrodo negativo). 
Em fontes de soldagem eletromagnéticas, a corrente de soldagem tem características semelhantes à corrente fornecida pela rede elétrica. Isto implica em limitações, como a impossibilidade de se controlar a freqüência de inversão de polaridade e o formato de onda de corrente. As fontes eletrônicas, que empregam formato de onda retangular, têm ampla vantagem sobre as fontes eletromagnéticas. No formato de onda senoidal, a transição da polaridade negativa para a positiva ocorre de forma gradativa, conduzindo a um maior tempo de extinção de arco, tornando mais difícil a sua re-ignição. $O$ formato de onda de corrente retangular, atenua em muito esta desvantagem, pois a transição entre a polaridade negativa e positiva ocorre de forma quase instantânea. Assim como a freqüência de inversão de polaridade, a predominância de uma polaridade sobre outra pode ser regulada, permitindo se utilizar um maior tempo de atuação de polaridade negativa em relação ao tempo de atuação da polaridade positiva, sendo o contrário também possível. O entendimento tradicional sobre o processo TIG CA induz a suposição de que um maior tempo de atuação da polaridade negativa em relação à polaridade positiva produz cordões de solda com maior penetração e o aumento do tempo de atuação da polaridade positiva, conduz a uma maior ação de remoção de óxidos e diminui a penetração.

A origem desta suposição está sobretudo nas afirmações presentes na literatura [4-7], de que o uso de CC- resultaria em um balanço de energia favorável a fusão do metal de base ( $70 \%$ do calor imposto ao metal de base e o restante imposto ao eletrodo). Uma soldagem nesta condição resultaria em cordões de solda estreitos e profundos. A situação seria exatamente a oposta quando na condição $\mathrm{CC}+$, gerando cordões mais largos e menos profundos como resultado. O processo com variação de polaridade é considerado uma situação intermediária em que haveria um balanço de $50 \%$ do calor gerado imposto à peça e $50 \%$ do calor gerado imposto ao eletrodo de tungstênio.

O trabalho de Fuerschbach [8] apresenta resultados onde as afirmações presentes na literatura [4-7] não se confirmam. Este autor realizou medições do aporte térmico de soldas de alumínio 1100 e aço inoxidável AISI 304 em juntas sobrepostas em aresta, usando processo Plasma CA, e não verificou mudança significativa nos valores registrados à medida que maiores tempos de polaridade positiva eram impostos. Por intermédio da análise da zona fundida, este autor verificou que é possível conseguir boas características de fusão em situações onde havia grande predominância da polaridade positiva sobre a negativa. Todavia, ao tentar determinar uma relação entre o aumento do tempo de polaridade positiva e as características da zona fundida, os resultados mostraram apenas uma grande dispersão. Em trabalho mais recente, Yarmuch e Patchett [9] determinaram uma relação diretamente proporcional entre o tempo de atuação da polaridade positiva e as características da zona fundida, em um liga de $\mathrm{Al}-\mathrm{Mg}$ 5083. À medida que o tempo de polaridade positiva aumentava, aumentavam penetração e área fundida. Apesar de alguns resultados distintos entre estes dois trabalhos, ambos atribuem à boa capacidade de fusão, encontradas com o uso de grandes tempos de eletrodo positivo, ao fato de que o aumento de tensão na região de queda catódica, característico do efeito de campo, aumenta a energia imposta ao metal de base e leva a uma melhoria das características de fusão do cordão de solda.

Em função do exposto, que evidencia certo conflito entre a literatura mais convencional e os últimos artigos publicados, este trabalho teve como motivação analisar os efeitos que o tempo de atuação da polaridade positiva tem sobre as características da zona fundida, a região de limpeza catódica e o comportamento da tensão e da potência na soldagem TIG CA do alumínio.

\section{Materiais e Métodos}

Cordões sobre chapa foram realizados de forma automatizada, utilizando o processo TIG CA, com o intuito principal de determinar o comportamento de fusão do alumínio à medida que se aumenta o tempo de atuação da polaridade positiva sobre o período de corrente. Foi definido um Percentual de Eletrodo Positivo \%EP, que é tempo de polaridade positiva sobre o período da onda de corrente, denotado pela Equação (2) onde: $\mathrm{t}(+)$ e t(-) são o tempo de polaridade positiva (ms) e o tempo de polaridade negativa $(\mathrm{ms})$, respectivamente. Estes tempos de atuação, tanto da polaridade negativa quanto da polaridade positiva são dados pela Tabela 1 , sendo que foram realizados três cordões de solda para cada combinação de parâmetros. As intensidades de corrente foram reguladas em $100 \mathrm{~A}$, tanto para a fase positiva quanto para a fase negativa, resultando em uma corrente eficaz (Ief) de $100 \mathrm{~A}$, em um formato de onda retangular. A faixa de $\%$ EP utilizada foi de $6,5 \%$ a $50 \%$. O motivo pelo qual este trabalho restringiu-se a esta faixa é explicado durante a exposição dos resultados (item 3.1).

$\% E P=\frac{t(+)}{t(+)+t(-)} \times 100$

Foi estabelecido um período de $20 \mathrm{~ms}$ assim como uma velocidade de soldagem de $20 \mathrm{~cm} /$ min para todos os experimentos. Uma fonte de soldagem INVERSAL 450, fabricada pela IMC [10], viabilizou a realização de todos os experimentos, pois permite a regulagem incondicional de todas as variáveis do processo.

O tipo de eletrodo utilizado foi o EWTh-2, com diâmetro de $3,2 \mathrm{~mm}$ e ângulo de afiação de $45^{\circ}$. Argônio comercialmente puro foi utilizado como gás de proteção a uma vazão de aproximadamente $7 \mathrm{l} / \mathrm{min}$. O ângulo entre o eletrodo e a peça de trabalho foi de $90^{\circ}$ e a distância eletrodo-peça (DEP) foi de $3 \mathrm{~mm}$.

Os corpos de prova de alumínio 1200 tiveram as seguintes dimensões: $240 \mathrm{~mm}$ x $100 \mathrm{~mm}$ e $3 \mathrm{~mm}$ de espessura. Todos os cordões de solda tiveram o comprimento aproximado de $200 \mathrm{~mm}$. A composição química nominal deste metal é apresentada na Tabela 2 [11]. Os corpos de prova receberam apenas uma limpeza simples com tecido embebido em álcool. Posteriormente, estes foram seccionados transversalmente ao cordão de solda na metade de seus comprimentos (100 mm a partir de qualquer extremidade), para retirada de amostras e realização de macrografias. Os ataques foram realizados com ácido fluorídrico $5 \% \mathrm{em}$ todas as amostras.

O SAP, sigla para Sistema de Aquisição Portátil [12], 
desenvolvido no LABSOLDA/UFSC, foi utilizado para capturar os sinais de corrente e tensão em cada experimento. Este sistema de aquisição permite o cálculo automático da Potência Média $(\mathrm{Pm})$, da Corrente Eficaz e Tensão Eficaz (Uef) do processo. Neste sistema, a Potência Média é calculada valendo-se da Equação (3). O tempo e a freqüência de aquisição foram de 2 segundos e $5 \mathrm{kHz}$, respectivamente.

$$
P m=\frac{\sum_{i=1}^{n} U_{i} I_{i}}{n}
$$

Onde:

$U_{i}=$ Tensão no instante $i$.

$I_{i}=$ Corrente no instante $i$.

$n=$ Número de pontos capturados pelo sistema.

Tabela 1. Parâmetros de soldagem para os ensaios variando o Percentual de Eletrodo Positivo (\%EP).

\begin{tabular}{|c|c|c|}
\hline $\mathbf{\% E P}$ & $\mathbf{t ( + )}(\mathbf{m s})$ & $\mathbf{t}(-) \mathbf{( m s )}$ \\
\hline $6,5 \%$ & 1,3 & 18,7 \\
\hline $10 \%$ & 2,0 & 18,0 \\
\hline $20 \%$ & 4,0 & 16,0 \\
\hline $35 \%$ & 7,0 & 13,0 \\
\hline $50 \%$ & 10,0 & 10,0 \\
\hline
\end{tabular}

Com a finalidade de produzir soldas em regime quase estacionário, o deslocamento da tocha era somente realizado após cerca de $5 \mathrm{~s}$ de arco aberto. Este era o tempo necessário para a formação de uma poça de fusão e para a uniformização do desgaste da ponta do eletrodo (sempre mais evidenciado em CA do que em CC-). Estes cuidados diminuem a influência sobre a largura do cordão de solda, produzindo-o de forma mais uniforme do início ao fim dos corpos de prova.

Tabela 2. Composição Química Nominal do Alumínio 1200 [11].

\begin{tabular}{|c|c|c|c|c|c|c|}
\hline $\mathbf{A l}^{1}$ & $\mathbf{S i}+\mathbf{F e}^{2}$ & $\mathbf{C u}^{2}$ & $\mathbf{M n}^{2}$ & $\mathbf{Z n}^{2}$ & $\mathbf{T i}^{2}$ & Outros $^{2}$ \\
\hline $99,0 \%$ & $1,0 \%$ & $0,05 \%$ & $0,05 \%$ & $0,10 \%$ & $0,05 \%$ & $\begin{array}{c}0,05- \\
0,15 \%\end{array}$ \\
\hline
\end{tabular}

${ }^{1}$ Percentagem requerida de alumínio. ${ }^{2}$ Percentagens máximas para estes elementos.

\section{Resultados e Discussão}

\subsection{Influência de \%EP sobre a Limpeza Catódica}

O intuito deste item é mostrar como o tempo de atuação da polaridade positiva atua sobre a faixa de limpeza catódica (a área adjacente ao cordão de solda na qual o óxido de alumínio foi removido pela ação da mancha catódica). Este item tem também como objetivo, explicar o motivo pelos quais os resultados apresentados neste trabalho restringem-se a faixa de $\%$ EP entre $6,5 \%$ e $50 \%$.

Primeiramente, o fator que limitou a utilização de \%EP maiores que $50 \%$ foi o desgaste do eletrodo de tungstênio. Este desgaste se mostrou tão pronunciado de modo que experimentos nestas condições foram considerados impraticáveis.

Contudo, o comportamento de fusão do alumínio quando se tem $\%$ EP maiores que $50 \%$, não é totalmente desconhecido. Fuerschbach [8] fez experimentos em uma faixa de percentual de eletrodo positivo entre $10 \%$ e $90 \%$ utilizando o processo Plasma CA e registrou valores altos de penetração no máximo e no mínimo tempo de polaridade positiva. Yarmuch e Patchett [9] apresentaram resultados onde a penetração aumenta linearmente para percentuais de eletrodo positivo entre $20 \%$ e $70 \%$. Estes autores utilizaram eletrodo de mesmo diâmetro $(3,2 \mathrm{~mm}) \mathrm{e}$ corrente maior (125 A) do que a utilizada neste trabalho, porém não se tem conhecimento de como lidaram com o desgaste do eletrodo.

Yarmuch e Patchett [9] não mostraram resultados para percentuais de eletrodo positivo menores do que $20 \%$ e, sendo assim, buscou-se investigar o comportamento de fusão do alumínio nesta faixa onde o desgaste de eletrodo de tungstênio não se mostrou como algo problemático.

Antes disso, no entanto, foi necessário determinar um valor mínimo de \%EP a partir do qual a remoção de óxido se mostrasse suficiente para as condições de soldagem destes experimentos (já mostradas no item 2). Para tanto, foram realizados cordões de solda sobre chapa, onde após cada ensaio, aumentava-se $0,5 \%$ no valor de $\% E P$, o que corresponde a uma variação de $0,1 \mathrm{~ms}$ no tempo de polaridade positiva. Por intermédio de uma simples inspeção visual, chegou-se a um valor de $6,5 \%$ para \%EP (correspondente a 1,3 ms). Alguns resultados são apresentados na Figura 3.a e 3.b onde é possível notar a presença de rugosidades na superfície do cordão de solda devido à escassez de limpeza catódica. Na Figura 3.c é apresentado um cordão de solda liso, com uma pequena área de limpeza circundante ao cordão (faixa de limpeza catódica), que foi considerado aceitável.

A Figura 4 mostra a influência de \%EP sobre a faixa de limpeza catódica. $\mathrm{Em} \% \mathrm{EP}=6,5 \%$ tem-se uma faixa bastante estreita enquanto que em $\% \mathrm{EP}=50 \%$ é possível notar uma faixa significativamente mais larga. Ou seja, a ação de limpeza é maior à medida que se aumenta \%EP. Outro aspecto que pode ser ressaltado é o aumento da largura do cordão de solda com o aumento de \%EP.

O efeito de \%EP sobre a limpeza catódica e a largura do cordão de solda decorre provavelmente do maior espalhamento do arco sobre a região de soldagem. Quanto maior o tempo de polaridade positiva, maior a movimentação da mancha catódica na busca por novos pontos onde a emissão de elétrons seja facilitada pela presença de óxido.

\subsection{Influência de \%EP sobre a Tensão e a Potência de Soldagem}

Os gráficos apresentados na Figura 5 correspondem às variações de Tensão Eficaz (Uef) e Potência Média (Pm) com o Percentual de Eletrodo Positivo (\%EP). Três séries de ensaios estão indicadas nestes gráficos, onde cada série corresponde à seqüência apresentada pela Tabela 1. Em função do mecanismo 

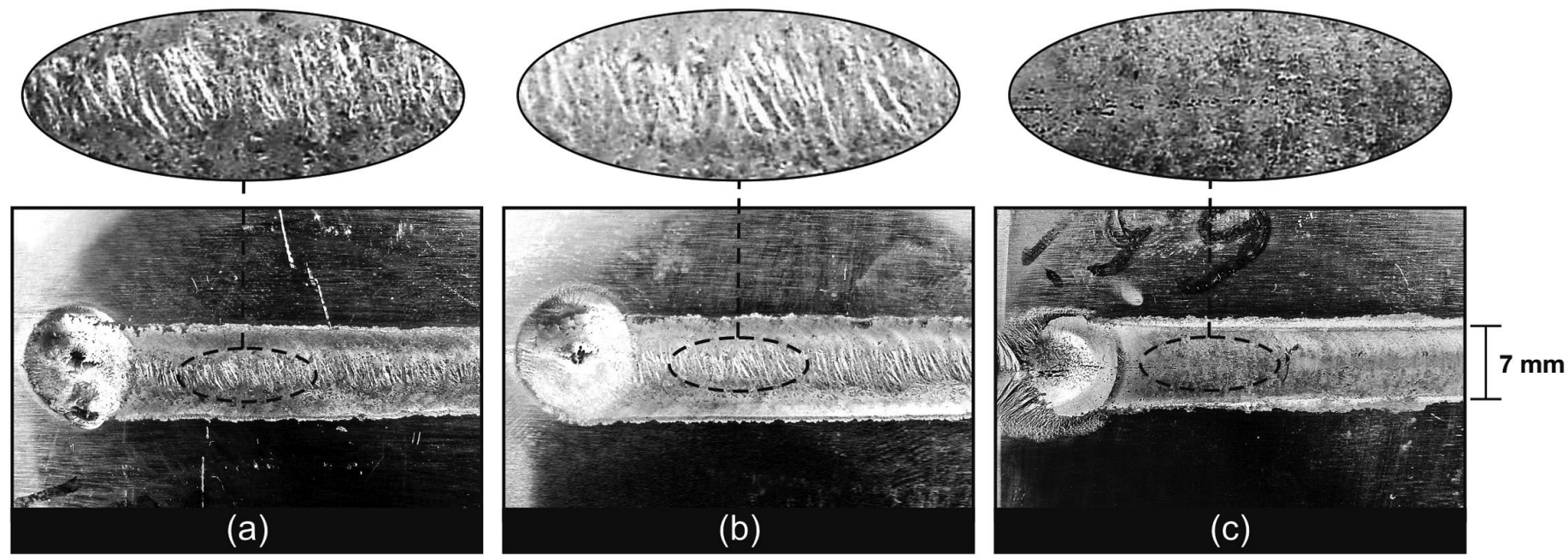

Figura 3. (a) Cordão de solda realizado com $\% \mathrm{EP}=5,0 \%$; (b) Cordão de solda realizado com $\% \mathrm{EP}=6,0 \%$; (c) Cordão de solda realizado com $\% \mathrm{EP}=6,5 \%$ e considerado de aparência aceitável.
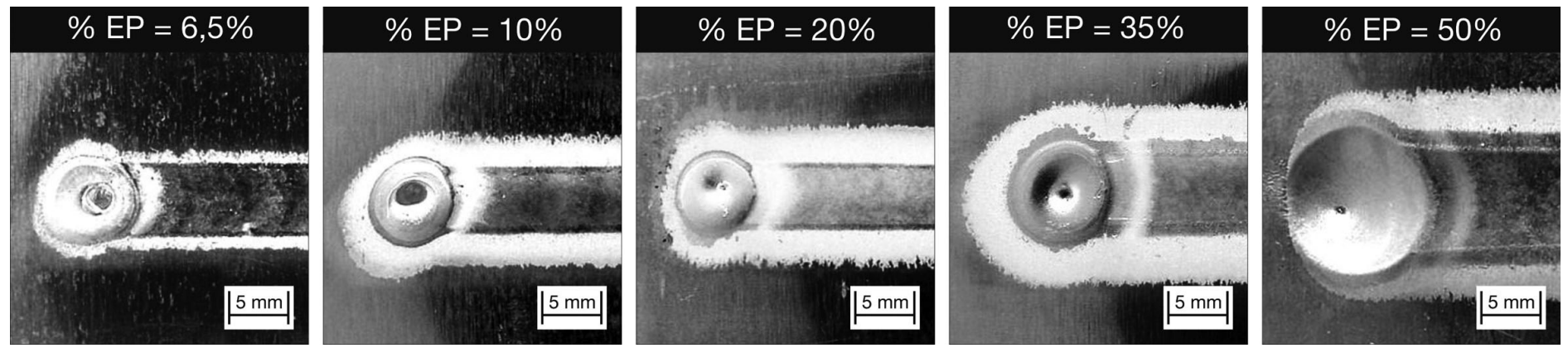

Figura 4. Aparência dos cordões de solda realizados durante os ensaios.

de emissão de elétrons por efeito de campo, que demanda um aumento de tensão na região de queda catódica, esperava-se um aumento gradual dos valores de Tensão Eficaz e Potência Média à medida que \%EP aumentasse. Em outras palavras, supunhase que quanto maiores os tempos de polaridade positiva, maiores seriam os valores de Uef e Pm em função da crescente necessidade de se extrair elétrons a partir de um cátodo não- termiônico (no caso, o alumínio). Isto, entretanto, não ocorre entre $\% \mathrm{EP}=6,5 \%$ e $20 \%$, havendo sim uma diminuição das intensidades de Uef e Pm. Somente entre \%EP $=20 \%$ e 50\% é que o comportamento se inverte.

Estes resultados podem ser explicados a partir de uma análise dos oscilogramas de tensão, que são apresentados na Figura 6 e correspondem a uma das três séries de ensaios. Estes deixam

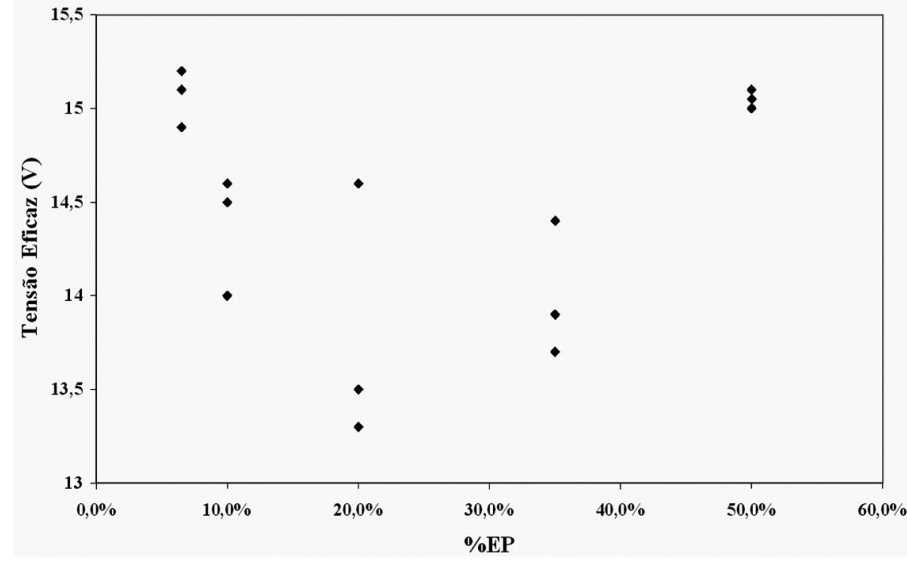

(a)

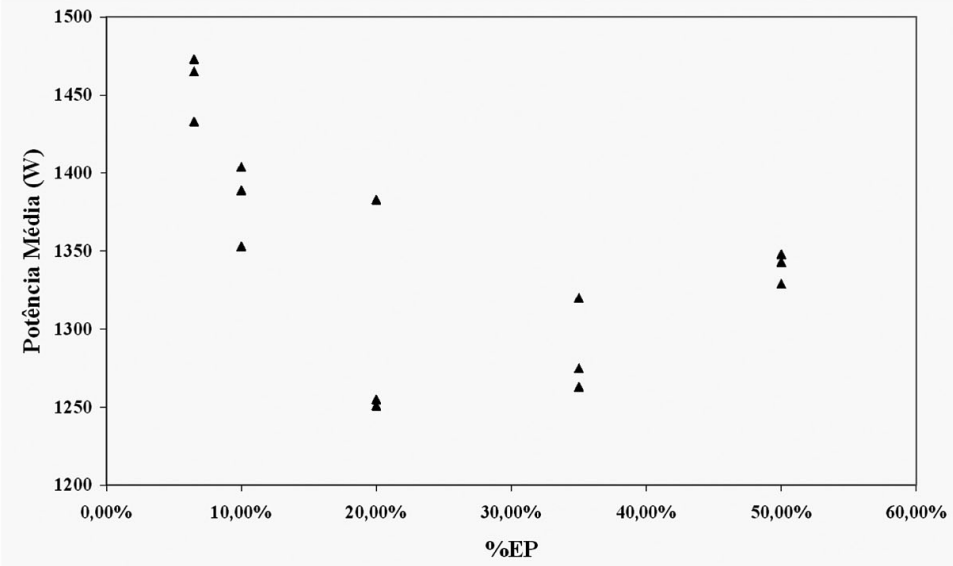

(b)

Figura 5. (a) Gráfico da relação entre Tensão Eficaz e Percentual de Eletrodo Positivo (\%EP). (b) Gráfico da relação entre Potência Média e Percentual de Eletrodo Positivo (\%EP). 

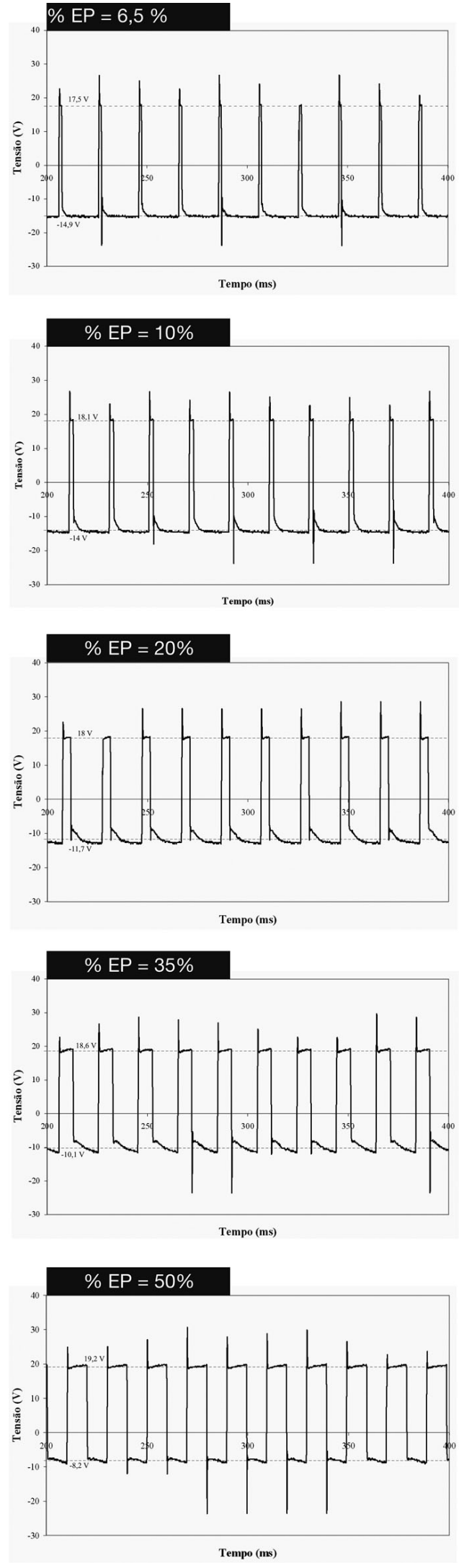

Figura 6. Oscilogramas de tensão correspondentes a cada

Percentual de Eletrodo Positivo testado. As linhas horizontais correspondem aos valores médios de tensão para cada polaridade. evidente uma diminuição gradual nos valores médios absolutos de tensão durante a fase negativa do processo, com o aumento de \%EP. Isto sugere uma situação mais propicia para a emissão de elétrons por intermédio do efeito termiônico, que pode estar relacionada com o sobre aquecimento do eletrodo de tungstênio durante as sucessivas fases positivas (onde o cátodo é a peça de trabalho) e até mesmo a uma melhora na condutividade elétrica do gás ionizado [13] em regiões próximas a ponta do eletrodo de tungstênio (quando este é o cátodo) causado pelo aumento de temperatura, permitindo que o fluxo de elétrons ocorra com uma tensão menor. Desta forma, quanto mais tempo de polaridade positiva $\mathrm{t}(+)$ é empregado, maior o calor gerado no eletrodo, menor a tensão necessária para a emissão termiônica de elétrons durante a fase negativa.

Situação semelhante a esta ocorre na relação tensão-corrente do arco TIG, onde em uma região de baixas correntes $(0<\mathrm{I}<70$ A) há um decréscimo para cada valor de tensão correspondente em função de o aumento de correntes causar maior aquecimento do cátodo (melhorando as condições de emissão termiônica) e do plasma (aumentando a condutividade elétrica) [14].

Conforme esperado, há realmente um aumento das tensões médias durante as fases positivas do processo, porém a variação de valores é menor em relação a que ocorre durante as fases negativas. Desta forma, de 6,5\% até $20 \%$ Uef cai, pois os valores de tensão durante as fases negativas caem de forma acentuada. A partir de $20 \%$ o comportamento se inverte, pois o tempo de polaridade $\mathrm{t}(+)$ torna-se mais significativo, compensando a queda nos valores de tensão apresentada nas fases negativas e, como resultado, Uef aumenta. A Tabela 3 apresenta a Tensão Média Negativa (valores absolutos) e a Tensão Média Positiva, que correspondem a tensão média calculada separadamente para cada polaridade. Estes dados corroboram o que foi discutido no parágrafo anterior, mostrando em valores a diminuição da Tensão Média Negativa e o aumento da Tensão Média Positiva à medida que \%EP aumenta.

Como a intensidade de corrente foi mantida constante tanto para as fases de corrente positivas, quanto negativas, o comportamento da Potência Média depende apenas das variações de tensão ocorridas. Logo o comportamento da Potência Média $(\mathrm{Pm})$ é semelhante ao da Tensão Eficaz (Uef). Também é possível identificar o comportamento da tensão por intermédio do cálculo separado das potências em cada uma das polaridades. A Figura 7 apresenta isto para as três séries de ensaios, onde a Potência $(+)$ representa a potência média somente das fases de polaridade positiva e Potência (-) representa a potência média somente das fases de polaridade negativa. O gráfico torna nítido que Potência (-) decresce muito mais acentuadamente com o aumento de $\%$ EP do que a Potência $(+)$ cresce. Conseqüentemente, a Potência Média $(\mathrm{Pm})$ diminui entre $6,5 \%$ até $20 \%$, quando passa a aumentar, pois o tempo de permanência do processo em polaridade positiva $\mathrm{t}(+)$ aumenta. 
Tabela 3. Tensões Médias calculadas separadamente para as polaridades negativa e positiva.

\begin{tabular}{|l|c|c|c|c|c|c|}
\cline { 2 - 7 } \multicolumn{1}{c|}{} & \multicolumn{3}{c|}{ Tensão Média Negativa (V) } & \multicolumn{3}{c|}{ Tensão Média Positiva (V) } \\
\hline $\mathbf{\%}$ Ensaio & $\mathbf{1}$ & $\mathbf{2}$ & $\mathbf{3}$ & $\mathbf{1}$ & $\mathbf{2}$ & $\mathbf{3}$ \\
\hline $\mathbf{6 , 5 \%}$ & 14,9 & 14,6 & 14,8 & 17,5 & 17,4 & 17,3 \\
\hline $\mathbf{1 0 \%}$ & 14,0 & 13,9 & 13,5 & 18,1 & 17,5 & 17,2 \\
\hline $\mathbf{2 0} \%$ & 11,7 & 11,6 & 13,1 & 18,0 & 17,8 & 18,7 \\
\hline $\mathbf{3 5 \%}$ & 10,1 & 10,45 & 10,2 & 18,6 & 19,3 & 18,1 \\
\hline $\mathbf{5 0 \%}$ & 8,2 & 7,9 & 8,0 & 19,2 & 19,3 & 19,4 \\
\hline
\end{tabular}

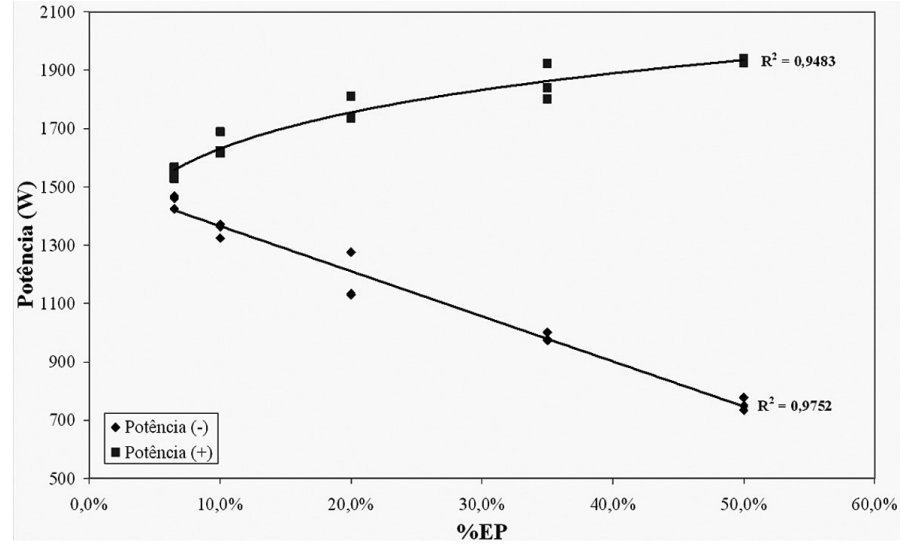

Figura 7. Comportamento da Potência Média durante as fases positivas e negativas.

\subsection{Influência de \%EP sobre a Zona Fundida}

Diferentemente do entendimento tradicional do processo TIG apresentado na literatura [4-7], os resultados apresentados neste item mostram situações onde houve uma melhoria nas características de fusão do metal de base com o aumento do tempo de atuação da polaridade positiva $\mathrm{t}(+)$.

A Figura 8 mostra as macrografias de todas as séries de ensaios, indicando o percentual \%EP e a Potência Média (Pm) medida. Comparando as macrografias correspondentes ao percentual $\%$ EP de $6,5 \%$ com a macrografia correspondente ao percentual \%EP de 35\%, têm-se características de fusão bastante semelhantes, mesmo com Potências Médias diferentes. A Figura 9 mostra os gráficos da Profundidade de penetração $(\mathrm{mm})$ e da Área da zona fundida $\left(\mathrm{mm}^{2}\right)$ em função da do aumento de \%EP, para todos os ensaios. Uma comparação pode ser feita, entre
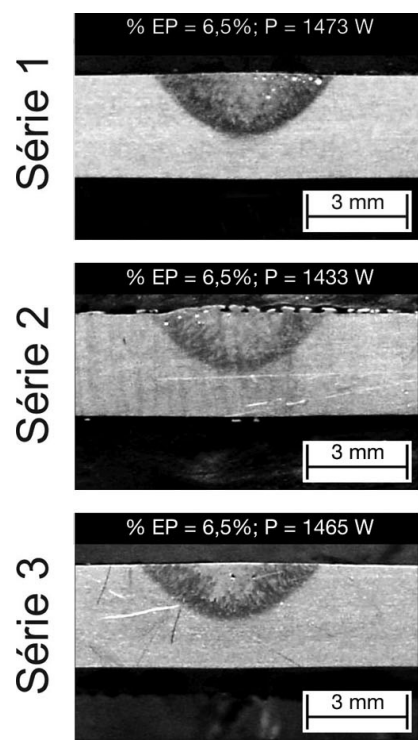
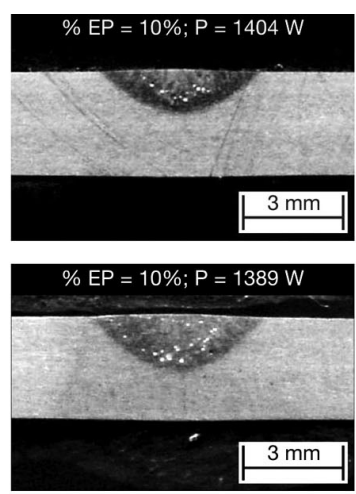

$\% E P=10 \% ; P=1353 \mathrm{~W}$

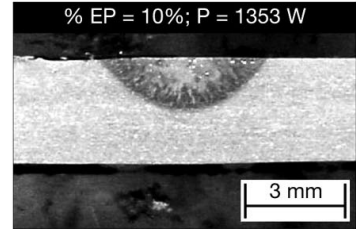

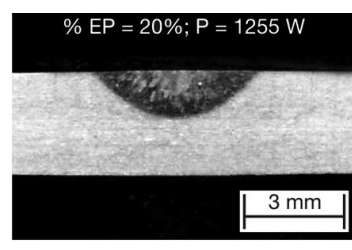

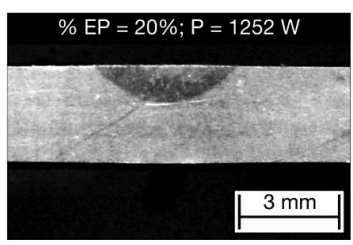

$\% E P=20 \% ; P=1383 \mathrm{~W}$

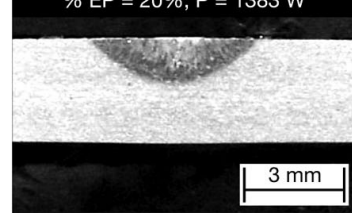

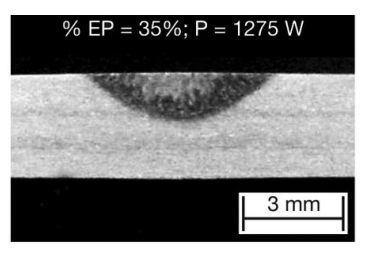

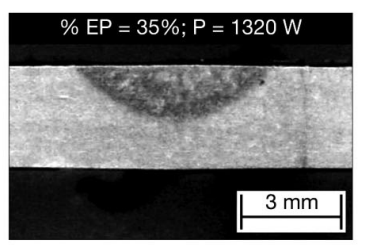

$\% E P=35 \% ; P=1263 \mathrm{~W}$

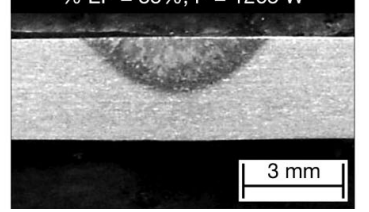

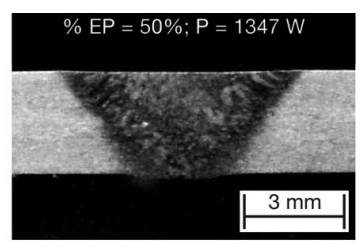

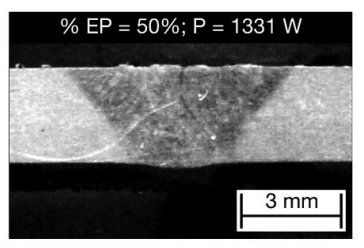

$\% E P=50 \% ; P=1345 \mathrm{~W}$

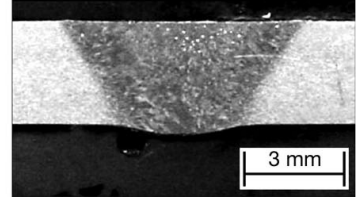

Figura 8. Macrografias correspondentes a todas as séries de ensaios realizados com variação de \%EP.

os dois extremos e em \%EP $=50 \%$ tem-se penetração e área fundida maior que em $\% \mathrm{EP}=6,5 \%$, mesmo apresentando uma Potência Média menor.

Considerando-se separadamente as duas polaridades, como na Figura 9, o processo fica alternando entre dois níveis diferentes de potência; um menor durante a fase negativa, outro maior durante a fase positiva. Aumentar \%EP significa que cada vez mais a poça de fusão fica submetida a potências maiores por um período de tempo maior durante a polaridade positiva. Entre os valores de $\% \mathrm{EP}=6,5 \%$ e $20 \%$, o tempo de atuação da polaridade positiva é pequeno e tem pouca influência sobre as características geométricas do cordão de solda. Com o aumento de \%EP, provavelmente a fase positiva começa a ter maior influência sobre a solda, pois aumenta o tempo na qual o processo permanece nesta e também a influência de outros fenômenos decorrentes da emissão de elétrons por efeito de campo, que serão discutidas a seguir. 


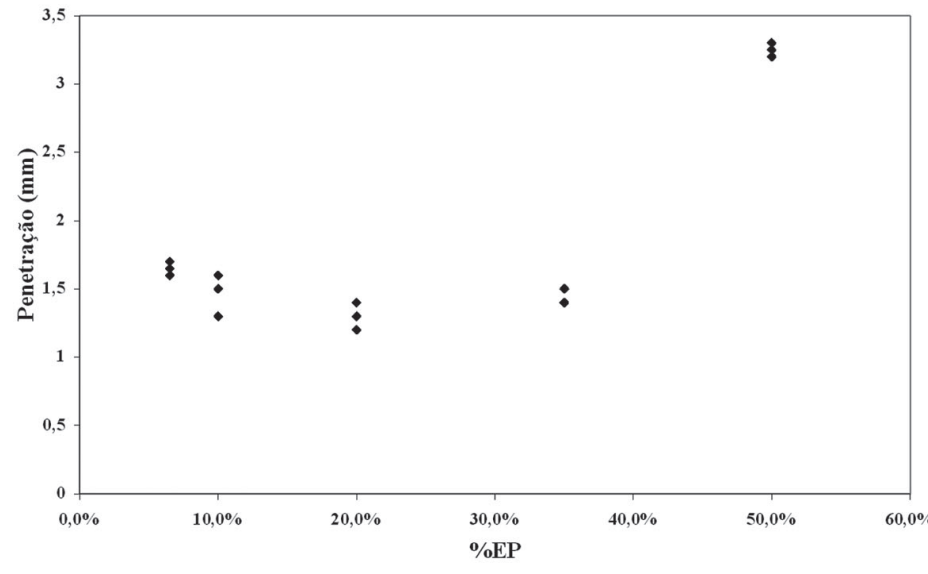

(a)

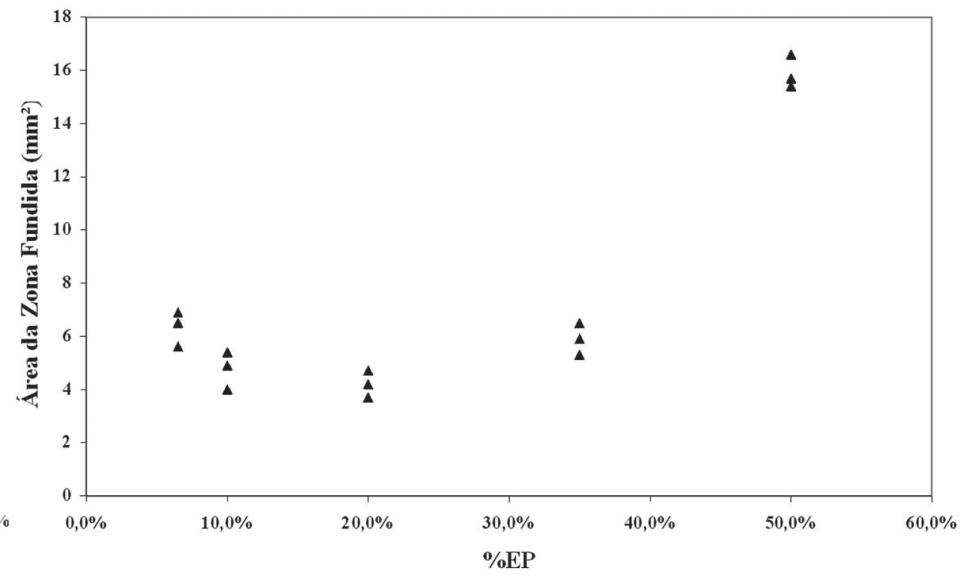

(b)

Figura 9. (a) Relação entre \%EP e Penetração (mm). (b) Relação entre \%EP e Área da zona fundida $\left(\mathrm{mm}^{2}\right)$.

Em seu trabalho, Fuerschbach [8] cita trabalhos de físicos como Cobine [15] que desenvolveram equações que estimam o aquecimento do cátodo e no ânodo quando os elétrons estão sendo emitidos por efeito termiônico. Este pesquisador define que o calor gerado em função dos fenômenos que ocorrem no ânodo $(\mathrm{Ha})$, é resultante do choque dos elétrons contra o mesmo. Estes elétrons entregam toda a energia acumulada em função da aceleração causada pelo gradiente de tensão existente na região de queda anódica (definido por $j V_{a}$, onde $j$ é a densidade de corrente e $V_{a}$ a queda de tensão anódica). Cada elétron que se choca contra o ânodo carrega consigo ainda uma energia adicional relacionada àquela necessária para emitir um elétron, ou função-trabalho ( $j \phi)$ [2], que também é entregue ao ânodo. Isto é resumido na Equação (4).

$$
H a=j\left(V_{a}+\phi\right)
$$

Os fenômenos que ocorrem no cátodo são diferentes. Neste o calor gerado $(H c)$ é estimado por intermédio da Equação (5). Do mesmo modo que o ânodo é cercado de cargas negativas (elétrons) o cátodo é cercado de cargas positivas (íons) [2]. Estes íons são acelerados pelo gradiente de tensão na região de queda catódica e fornecem energia (definido por $j_{i} V_{c}$, onde $j_{i}$ é a densidade de corrente carregada pelos íons e $V_{c}$ a queda de tensão catódica). Energia adicional é suprida pelos íons quando estes são neutralizados na superfície do cátodo $\left(j_{i} V_{i}\right.$, onde $\mathrm{V}_{\mathrm{i}}$ é o potencial de ionização do plasma). Energia é perdida na emissão de elétrons ( $J_{e} \phi$, onde $j_{e}$ é a densidade de corrente carregada por elétrons emitidos termionicamente). Ou seja, para cada elétron emitido é necessária uma determinada energia, no caso, a função-trabalho $(\phi)$, e esta energia é provida pelo cátodo. Autores como Fuerschbach [1] referem-se a esta perda de calor como efeito de resfriamento (cooling effect). VonEngel [16], por exemplo, observa que há um resfriamento substancial pela emissão de elétrons para o eletrodo de tungstênio, na polaridade negativa, de modo que o desgaste provocado neste é muito pequeno. Além desta perda, uma porção de energia também é perdida pela neutralização de íons positivos por elétrons $\left(j_{i} \phi\right)$.

$$
H c=j_{i} V_{c}-j_{i} \phi+j_{i} V_{i}-j_{e} \phi=j_{i}\left(V_{c}+V_{i}-\phi\right)-j_{e} \phi
$$

Durante a soldagem TIGCA, quando o eletrodo de tungstênio torna-se o ânodo na fase positiva de corrente, não emitindo mais elétrons, as perdas de calor no eletrodo de tungstênio denotadas por $\left(J_{e} \phi\right)$, não mais ocorrem, e isto gera grande desgaste do tungstênio. Durante esta mesma fase, a peça de trabalho passa a suprir elétrons por efeito de campo e, segundo outro físico citado por Fuerschbach, VonEngel [16], a emissão por efeito de campo diferencia-se do efeito termiônico, "pois causa uma distribuição de energia distinta e nenhum efeito de arrefecimento ocorre". Ou seja, as perdas causadas por cada elétron emitido são aplicáveis somente a materiais que sustentam a emissão de elétrons por intermédio de efeito termiônico e o alumínio não se encaixa neste perfil. Se nenhuma perda ocorre para cada elétron emitido, maior calor é gerado na peça de trabalho e isto se traduz em uma melhoria nas características de fusão do cordão de solda.

$\mathrm{O}$ desgaste causado no eletrodo de tungstênio, quando na polaridade positiva, é apontado por Yarmuch e Patchett [9] como uma das possíveis causas que levaram a equívocos ao se tentar avaliar os efeitos da polaridade sobre o balanço térmico do processo TIG. Em CC+ positivo não se tem nenhum efeito de resfriamento sobre o eletrodo de tungstênio (pois este não está emitindo elétrons) o que causa grande desgaste sugerindo que a geração de calor no eletrodo é muito maior do que na peça de trabalho. Estes autores descrevem também as dificuldades de se investigar o processo TIG exclusivamente nas condições $\mathrm{CC}+\mathrm{e}$ CC- devido a dificuldade de se obter a duplicação de resultados além, é claro, do desgaste extremo do eletrodo em $\mathrm{CC}+$. Neste caso, para tentar atenuar o desgaste do eletrodo pode-se tentar utilizar eletrodos de grandes diâmetros e correntes de soldagem bastante baixas. Contudo, no caso do alumínio, é impraticável a utilização de CC- devido à necessidade de limpeza catódica.

Ainda relacionado ao aumento de fusão obtido em altos percentuais de eletrodo positivo, na polaridade negativa a emissão de elétrons ocorre por intermédio de efeito termiônico o que demanda menor tensão na região de queda catódica. $\mathrm{Na}$ polaridade positiva, a emissão de elétrons se dá por efeito de campo o que demanda uma maior tensão na região de queda 
catódica. Isto resulta em maior geração de calor sobre a superfície da peça de trabalho e contribui para um aumento de fusão do metal de base à medida que se aumenta a atuação da polaridade positiva no processo TIG CA.

Assim, a maior fusão encontrada em grandes percentagens de eletrodo positivo, está diretamente relacionada ao mecanismo de emissão de elétrons. Os fenômenos relacionados ao efeito de campo se associam de forma que um aumento de \%EP acarretou em um aumento de penetração e na área da zona fundida. Contudo, este aumento ocorreu apenas quando o efeito de campo teve um papel importante na emissão de elétrons (ou seja, quando $\%$ EP foi maior que $20 \%$ ).

\section{Conclusões}

- Os resultados genéricos do presente trabalho mostraram que as propriedades resultantes da soldagem TIG CA do alumínio, não são criteriosamente apresentadas na literatura corrente e apenas alguns artigos específicos apresentam resultados mais concordantes com os aqui apresentados.

- As maiores profundidades de penetração e áreas fundidas foram encontradas em Percentuais de Eletrodo Positivo onde o efeito de campo teve papel importante na emissão de elétrons, e, por conseguinte, os fenômenos decorrentes deste, contribuíram para maior fusão do metal de base.

- Em função do que expõe genericamente a literatura, as fontes de energia para soldagem TIG CA indicam regulagens, no tocante a maior ou menor penetração, de maneira equivocada. Para maiores tempos de polaridade positiva, que significam maior eficiência de limpeza catódica, as fontes indicam também menor penetração. Isto é apenas verdadeiro para um percentual de eletrodo positivo (\%EP) até cerca de $20 \%$. Após isto, a penetração aumenta.

- Do ponto de vista de uma situação de menor desgaste do eletrodo, a situação mais indicada para se ter maior fusão é com apenas $6,5 \%$ de $\% \mathrm{EP}$, que para o citado alumínio se revelou suficiente em termos de limpeza catódica.

- Os comportamentos das curvas de Tensão Eficaz (Uef) e Potência Média (Pm), apresentados nos gráficos da Figura 3, foram explicados pela análise do comportamento da tensão durante as polaridades negativa e positiva, separadamente. Houve uma diminuição em Uef e Pm entre $6,5 \%$ e $20 \%$ de $\% \mathrm{EP}$, enquanto estes valores aumentaram para percentagens maiores que $20 \%$.

\section{Agradecimentos}

A toda equipe do LABSOLDA, em especial a Ricardo Campagnin, Hellinton Direne, Ivan Pigozzo, Marcelo Okuyama e Tiago Vieira.

\section{Referências}

[1] SUBAN, M.; TUSEK, J. Dependence of Melting Rate in MIG/MAG Welding on the Type of Shielding Gas Used. Journal of Materials Processing Technology, n. 119, p. 185192, dez. 2001.
[2] KEY, J.F, Arc Physics of Gas-Tungsten Arc Welding. ASM Handbook - Welding Brazing and Soldering Vol 6, p. 81-92, 1993.

[3] LANCASTER, J.F.; The Physics of Welding. 2. Pergamom Press, 1986. 335 p.

[4] MATHERS, G. The Welding of Aluminium and its Alloys. 1. ed. Cambridge: CRC Press, 2002, 233 p.

[5] Welding Handbook - AWS; Vol. 2, Welding Processes, 1991. $955 \mathrm{p}$.

[6] KEN-HICKEN, G. Gas Tungsten Arc Welding - ASM Handbook - Welding Brazing and Soldering Vol. 6, p. 597-602, 1993.

[7] GERKEN, J.M. Gas Tungsten Arc Welding. James F. Lincoln Arc Welding Foundation. 42 p.

[8] FUERSCHBACH, P.W. Cathodic Cleaning and Heat Input in Variable Polarity Plasma Arc Welding of Aluminum. Welding Journal, v. 77, n. 07, p. 76s-85s, fev. 1998.

[9] YARMUCH, M.A.R.; PATCHETT, B.M. Variable AC Polarity GTAW Fusion Behaviour in 5083 Aluminum. Welding Journal, v. 86, n. 02, p. 196s-200s, jul. 2007.

[10] IMC-SOLDAGEM. Manual do Equipamento. Apresenta as características da fonte de soldagem Inversal 450. Disponível em $<$ http://www.imc-soldagem.com.br/inversal.html $>$. Acessado em 16/09/2008.

[11] ASM Handbook - ASM; Vol. 2, Properties and Selection: Nonferrous Alloys and Special Purpose Materials, 1992.

[12] INSTITUTO DE SOLDAGEMEMECATRÔNICA. Manual do Sistema. Apresenta características do SAP. Disponível em $<$ http://www.labsolda.ufsc.br/projetos/projetos_viabilizados/ sap_1.php>. Acessado em 16/09/2008.

[13] MARYA, M.; EDWARDS, G.R.; LIU, S. An investigation on Effects of Gases in GTA Welding of a Wrought AZ80 Magnesium Alloy. Welding Journal, v. 83, n.07, p.203s-212s, Jul. 2004.

[14] SAEDI, H.R. Transient Response of Plasma Arc and Weld Pool Geometry for GTAW Process. 1986. 142 f.. Tese (Mechanical Engineering Doctorate), Massachusetts Institute of Techonology, Cambridge, 1986.

[15] COBINE, J.D. Gaseous Conductors. McGraw-Hill, 1941.

[16] VONENGEL, A. Ionized Gases. Clarendon Press. 1965. 